\title{
Erratum to: Selenium as a Feed Supplement for Heat-Stressed Poultry: a Review
}

\author{
Mahmood Habibian $^{1}$ - Ghorbanali Sadeghi ${ }^{1} \cdot$ Shahab Ghazi $^{2}$ • \\ Mohammad Mehdi Moeini ${ }^{2}$
}

Published online: 2 April 2015

(C) Springer Science+Business Media New York 2015

Erratum to: Biol Trace Elem Res

DOI 10.1007/s12011-015-0275-x

The Authors wish to make the following corrections:

The reference number [54] should be changed to [55] on page 3 , and the reference number [55] should be changed to [54] on pages 3 and 5, as well as in Table 1. Also on page 5 "Sahin et al. [13]" should be "Sahin and Kucuk [54]." Finally, the subheadings "Nutrient Digestibility", "Antioxidant Status" and "Immunocompetence" should have been italicized, not boldface.

The Authors and Editors-in-Chief regret the errors.

The online version of the original article can be found at http://dx.doi.org/ 10.1007/s12011-015-0275-x.

Mahmood Habibian

mahmood_habibiyan@yahoo.com

1 Department of Animal Science, Faculty of Agriculture, University of Kurdistan, Sanandaj, Iran

2 Department of Animal Science, College of Agriculture and Natural Resources, Razi University, Kermanshah, Iran 